\title{
(2) OPEN ACCESS \\ Association of disability with mortality in the Spanish adult non-institutionalised population
}

\author{
Javier Damián 지 1,2 Alicia Padron-Monedero 지 , Javier Almazán-Isla, ${ }^{1,2}$ \\ Fernando J García López, ${ }^{1,2}$ Jesús de Pedro-Cuesta, ${ }^{1,2}$ Roberto Pastor-Barriuso 1,4
}

\begin{abstract}
- Additional supplemental material is published online only. To view, please visit the journal online (http://dx. doi.org/10.1136/jech-2021217421)
\end{abstract}

1 National Center for Epidemiology, Institute of Health Carlos III, Madrid, Spain ${ }^{2}$ Consortium for Biomedical Research in Neurodegenerative Diseases (CIBERNED), Madrid, Spain

${ }^{3}$ National School of Public Health, Institute of Health Carlos III, Madrid, Spain

${ }^{4}$ Consortium for Biomedical Research in Epidemiology and Public Health (CIBERESP), Madrid, Spain

\section{Correspondence to} Dr Alicia Padron-Monedero, Escuela Nacional de Sanidad, Instituto de Salud Carlos III, Av/ Monforte de Lemos 5, Madrid 28029, Spain;

a.padronm@isciii.es

Received 3 June 2021

Accepted 24 October 2021

\section{Check for updates}

c) Author(s) (or their employer(s)) 2021. Re-use permitted under CC BY-NC. No commercial re-use. See rights and permissions. Published by BMJ.

\begin{tabular}{|l|}
\hline To cite: Damián J, \\
Padron-Monedero A, \\
Almazán-Isla J, et al. J \\
Epidemiol Community Health \\
Epub ahead of print: [please \\
include Day Month Year]. \\
doi:10.1136/jech-2021- \\
217421 \\
\hline
\end{tabular}

\begin{abstract}
Background There are scant studies focused on measuring the association between disability and allcause mortality based on large representative national samples of the community-dwelling adult population; moreover, the number of such studies which also include cause-specific mortality is yet lower.

Methods Longitudinal cohort study that used baseline data from 162381 adults who participated in a countrywide disability survey (2008). A nationally representative sample was selected and interviewed in their homes. We present data on people $\geq 18$ years. Disability was considered as any substantial limitation found on a list of 44 life activities that have lasted or are expected to last more than 1 year and originate from an impairment. Cause-specific mortality data were obtained from the Spanish Statistical Office. Subjects contributed follow-up time from baseline interview until death or the censoring date (31 December 2017). We computed standardised rate ratios (SRRs), with age, sex, living with a partner and education level distribution of the total group as standard population.
\end{abstract}

Results Adults with disability (11\%) had an adjusted mortality rate more than twice as high as adults without disability (SRR 2.37, 95\% CI 2.24 to 2.50). The increased mortality risk remained over the 10-year follow-up period. Mortality due to diseases of the nervous system (SRR 4.86, 95\% Cl 3.93 to 6.01), diseases of the musculoskeletal system (SRR $3.45,95 \% \mathrm{Cl} 2.18$ to 5.47 ), infectious diseases (SRR 3.38, 95\% Cl 2.27 to 5.01) and diabetes mellitus (SRR 3.56, 95\% Cl 2.71 to 4.68) was particularly high in those with disability.

Conclusions All-cause mortality rates are markedly higher among adults with disability. Preventive measures and health promotion initiatives are needed to reduce mortality risk in this population. Special attention should be paid to disabled people with certain specific diseases.

\section{INTRODUCTION}

Disability is an umbrella term, covering impairments, activity limitations and participation restrictions. Impairments are problems in body function or structure; an activity limitation is a difficulty in executing a task or action; whereas participation restriction refers to problems in involvement in life situations. $^{1}$

There are many types of disabilities, such as those that affect vision, hearing, movement, thinking, remembering, learning, communicating, mental health and social relationships. ${ }^{2}$ Disability, in either of its different types, could appear in relation to very different conditions, injuries or diseases. ${ }^{2}$
The prevalence of disability is largely heterogeneous because of real differences in the prevalence of its determinants but also due to different definitions and sources. It can range between $10 \%$ and $15 \%$ of the population. ${ }^{3}$ The association between disability and health is also complex. Disability can be the consequence of disease or health conditions but also their cause, since it has been reported that $87 \%$ of people with disability have at least one secondary health condition. ${ }^{4}$ So, different disabilities have been identified as determinants for multiple conditions that are potentially related to an increased risk of death, such as depression, ${ }^{5}$ decubitus ulcers, ${ }^{5}$ a reduced immune function, ${ }^{5}$ pulmonary infections, ${ }^{5}$ obesity $^{67}$ and weight problems in general, ${ }^{4}$ bowel and bladder problems, ${ }^{4}$ asthma, ${ }^{4}$ cardiovascular problems, ${ }^{7}$ anxiety ${ }^{4}$ and more propensity to injuries and falls, ${ }^{4}$ among others. Disabilities can also cause difficulty getting out into the community, ${ }^{4}$ sleep problems ${ }^{4}$ and muscle spasms ${ }^{4}$ that could be related to poorer mental health including higher risk of suicide. ${ }^{5}$ Moreover, despite advances in personalised care, health professionals are not always properly prepared to diagnose and treat the secondary conditions derived from disability, ${ }^{5}$ which can lead to a worse prognosis. Thus, it is reasonable to expect that disability may be associated with an increased risk of death.

Finally, as disability rates are strongly increasing in Europe, ${ }^{8}$ it becomes important to provide epidemiological information about potential consequences of this trend, such as mortality, all-cause and cause-specific. Many studies show associations between disability and mortality in older populations, but there are few studies that primarily focus on measuring this association in representative samples of adult populations.

In 2008, the Spanish Statistical Office (INE) carried out a large nationwide survey on disability. ${ }^{9}$ This survey formed the baseline cohort for a subsequent follow-up study on mortality.

The main objective of this research was to measure the association of disability with all-cause and cause-specific mortality in a representative sample of the adult population in Spain.

\section{METHODS}

\section{Study population}

Baseline data came from the 2008 Spanish Survey on Disabilities, Personal Autonomy and Dependency (Encuesta Sobre Discapacidades, Autonomía Personal y Situaciones de Dependencia (EDAD2008)). ${ }^{9}$ 
The study population covered by EDAD2008 consisted of a two-step, stratified, random sample of the community-dwelling population, representative of each province: first, a sample of census tracts was drawn, and a sample of family dwellings was then randomly selected within each tract. Thereafter, all households within the dwelling were group screened, and one member of each household was interviewed as the main informant. Subjects identified with a possible disability were then interviewed in depth. The interviews were conducted between November 2007 and February 2008. A total of 258187 people living in 91290 households were thus screened for disability. Data on mortality could be obtained for 207529 subjects (80.4\%). Of these, 162381 people aged 18 years or over formed the study sample. Missing data on mortality were due to difficulties in identifying subjects.

\section{Study variables}

In the EDAD2008 survey, disability was considered as any important limitation to carrying out an activity, which had lasted or was expected to last more than 1 year and whose origin was an impairment. A person was considered to have a disability even if it had been overcome with the use of external technical aids, or with the help and/or supervision of another person. For screening purposes, a list of 44 questions about possible disabilities-read verbatim-was presented to the main informant of each household (see online supplemental material). The list addressed the following eight domains: vision; audition; communication; learning and application of knowledge and performance of tasks; mobility; self-care; domestic life; interaction and interpersonal relationships. People who answered affirmatively to at least one of these questions formed the disability group. To assess disability severity, we used two methods. First, a reported score based on the International Classification of Functioning Disability and Health (ICF) Checklist. ${ }^{10}$ Twenty-nine EDAD2008 items were backcoded to specific domains of the ICF Checklist and by rating the recorded difficulty performing specific tasks. A global ICF score was derived, although lacking data for domains $\mathrm{d} 1$, 'Learning and applying knowledge', d8, 'Major Life Areas' and d9, 'Community, Social and Civic Life'. Disability severity was categorised into mild, moderate, severe and complete disability according to ICF categories. The categories of severe and complete disability were collapsed together; consequently, a four-category variable was analysed (no disability; mild; moderate; severe/complete). A detailed explanation of these procedures can be found elsewhere. ${ }^{11}$ As a second step, the number of disabilities identified for each person was grouped together to produce four categories: $0,1-3,4-9$ and $10-42$.

Age, marital status and educational level attained were obtained by interview.

Mortality data were provided by the INE. Underlying causes of death were coded using the International Statistical Classification of Diseases and Related Health Problems, 10th Revision reduced list. ${ }^{12} 13$ These include 102 different causes of death grouped into 17 types.

Subjects contributed follow-up time from their baseline interview until death or the censoring date, 31 December 2017.

\section{Analysis}

Overall baseline proportions, means and crude rates were weighted with sampling weights. These were computed as the inverse of each participant's baseline selection probability, corrected by non-response.
To estimate the adjusted association of disability with mortality-all-cause and cause-specific-we computed standardised rate ratios (SRRs) via inverse probability weighting, ${ }^{14} 15$ taking the baseline distribution of age $(18-39,40-64,65-74$, $\geq 75$ years), sex (women or men), living with a partner (yes or no) and educational level (less than primary, primary, secondary, preuniversity, university) for the total population as the standard. Weights for subjects were computed as the inverse of the conditional probability of being in their own exposure category, computed through sampling-weighted logistic regression models with disability as dependent variable, and the independent variables above as covariates. In the case of the four-category disability variables (ICF severity and number of disabilities), these probabilities were estimated through multinomial logistic regression models. Weights were then multiplied by the unconditional probability of being in their own exposure category. These stabilised weights were finally multiplied by the sampling weights. We computed weighted Poisson regression models for estimating standardised rates and rate ratios with these final weights, with disability as the independent variable and the logarithm of each observed person-year as the offset variable. To evaluate time-dependent effects, we computed 10 SRRs with increasing follow-up time, from 1 to 10 years.

Population attributable fraction for disability was calculated with the formula $f(\mathrm{SMR}-1) / \mathrm{SMR},{ }^{16}$ where $f$ is the fraction with disability among deaths and SMR is the standardised mortality ratio. SMR was computed via inverse probability weighting using the baseline distribution of the disability group as standard. In this case, the weight for the $i$ subject was estimated by fitting a sampling-weighted logistic regression model with disability status $(E)$ as dependent variable and age, sex, living with a partner and educational level as independent variables $(Z)$, and computed as:

$$
w_{i}=\frac{P\left(E=1 \mid Z=z_{i}\right)}{P\left(E=e_{i} \mid Z=z_{i}\right)}
$$

Thus, weights were 1 for disability subjects, and the conditional disability odds for non-disability. ${ }^{17}$ Final weights were the product of sampling weights and standardisation weights and applied in a Poisson model to obtain the SMR. CIs for the population attributable fraction were calculated with the formula proposed by Greenland. ${ }^{18}$

Due to the complex sampling design, we used appropriate methods to account for the effect of stratification and clustering on SEs. Analyses were run with Stata V.15. ${ }^{19}$

\section{RESULTS}

Baseline characteristics of the study population are shown in table 1 . The prevalence $(95 \% \mathrm{CI})$ of disability was $11.0 \%(10.7 \%$ to $11.2 \%$ ), and was higher in older people, women, participants not living with a partner, and those with lower educational levels.

There were 17132 deaths in 1541910 person-years follow-up. The median follow-up was 10.0 years. The sampling weighted mortality rates $(95 \% \mathrm{CI})$ per 1000 person-years, were 10.0 (10.1 to 10.6), for the overall population, 50.8 (49.3 to 52.3) for the disability group and 6.4 (6.2 to 6.6) for the non-disability group, for a crude rate ratio of 7.93 (7.63 to 8.24).

Table 2 shows the standardised mortality rates for the whole group and for subgroups of sex and age. The standardised rates per 1000 person-years were 20.03 for the disability group and 8.47 for non-disability group, for an SRR of 2.37. The standardised rate difference (SRD) between the mortality of the disability group and the non-disability group was 11.56 per 1000 person-years. There was little difference in the relative estimates 


\begin{tabular}{llll}
\hline $\begin{array}{l}\text { Table } 1 \\
\text { over* }\end{array}$ & Baseline characteristics of study population aged 18 or \\
\hline & All & Disability & No disability \\
\hline Total, $\mathrm{n}(\%)$ & $162381(100)$ & $18600(11)$ & $143781(89)$ \\
\hline Age, years, mean (SD) & $48(18)$ & $66(18)$ & $45(17)$ \\
\hline $\begin{array}{l}\text { Age group, years (\%) } \\
18-39\end{array}$ & 39 & 9 & 42 \\
\hline $40-64$ & 41 & 31 & 42 \\
\hline $65-74$ & 11 & 20 & 10 \\
\hline$\geq 75$ & 10 & 40 & 6 \\
\hline Sex, women (\%) & 51 & 60 & 50 \\
\hline Lives with partner (\%) & 65 & 54 & 66 \\
\hline Educational level attained (\%) & & & \\
\hline Illiterate and less than primary & 16 & 44 & 13 \\
\hline Primary (6-12 years old) & 25 & 30 & 25 \\
\hline Secondary (12-16 years old) & 14 & 10 & 15 \\
\hline Preuniversity (16-18) & 22 & 9 & 23 \\
\hline University (18 and more years old) & 23 & 7 & 25 \\
\hline
\end{tabular}

*Unweighted counts and weighted percentages (sampling weights).

by sex, with SRR of 2.37 for women and 2.38 for men. There was a clear gradient by age with younger people showing higher SRRs and older groups with notably higher SRDs.

The SMR $(95 \% \mathrm{CI})$ was 1.92 (1.83 to 1.99$)$ and the fraction of persons with disability among the deceased was 0.44 , for a population attributable fraction $(95 \% \mathrm{CI})$ of 0.21 (0.20 to 0.22$)$.

Online supplemental figure 1 and 2 show the estimates for increasing follow-up years. The SRRs were very high in the first years of follow-up but remained high and over 2 throughout the 10 years. SRDs also declined with follow-up time.

Tables 3 and 4 show the association of disability severity with mortality, measured both by the ICF score and the number of disabilities suffered by each subject. In both cases, a strong gradient was evident.

Table 5 shows the cause-specific mortality associated with disability. Disability was clearly associated with mortality in all groups. The SRR was particularly high in the following groups: diseases of the nervous system (4.86), diseases of the musculoskeletal system (3.45), infectious diseases (3.38), diseases of the genitourinary system (3.10), and endocrine diseases (3.08); and was lower for neoplasms (1.74). In terms of absolute impact, as measured by the SRD, diseases of the circulatory system and neoplasms showed higher figures, with 3.24 and 2.13 deaths per 1000 person years, respectively.

The association between disability and more specific causes of death can be found in online supplemental table 1 . Some of
Table 3 Association of ICF disability severity with mortality

\begin{tabular}{llll}
\hline Severity & SR* & SRD & SRR \\
\hline $\begin{array}{l}\text { No } \\
\text { disability }\end{array}$ & $8.49(8.24-8.74)$ & 0 (ref.) & 1 (ref.) \\
$\begin{array}{l}\text { Mild } \\
\text { disability }\end{array}$ & $15.26(14.3-16.23)$ & $6.77(5.81-7.74)$ & $1.80(1.68-1.92)$ \\
$\begin{array}{l}\text { Moderate } \\
\text { disability }\end{array}$ & $36.84(32.8-40.88)$ & $28.35(24.31-32.38)$ & $4.34(3.88-4.85)$ \\
$\begin{array}{l}\text { Severe/ } \\
\text { complete } \\
\text { disability }\end{array}$ & $88.85(68.81-108.9)$ & $80.36(60.31-100.40)$ & $10.46(8.33-13.14)$ \\
\hline
\end{tabular}

*SR per 1000 person-years, with the baseline total population distribution of age, sex, living with a partner and education as standard.

ICF, International Classification of Functioning Disability and Health; SR, standardised rate; SRD, standardised rate difference; SRR, standardised rate ratio.

these estimates are unstable due to small number of cases (for a simple measure of precision for rate ratio estimates, we provide the ratio of the upper to lower confidence limits; as a somewhat arbitrary guide, estimates with ratios below 2 are deemed very precise and above 10 are very unstable. Diseases showing reasonable stable estimates (Ul/Ll less than 5) and strong associations (SRR of 2.5 or more) deserve particular attention.

\section{DISCUSSION}

In this large follow-up study, we found mortality to be more than twice higher in persons with disability, with a population attributable fraction of $21 \%$. This could be translated to a figure of 87309 annual deaths attributable to disability in the Spanish adult population (415757 total deaths in people aged $\geq 18$ years, estimated for 2019). ${ }^{20}$ We also found that the risk remains high over time. Interestingly, we found a clear increase in risk for almost all of causes of death.

A limited number of works have primarily measured mortality associated with disability in representative samples. In general, the estimates presented by these studies are similar to those of the present article. Majer et al found 65\% higher mortality in the Dutch population over 55 years of age (average adjusted $\mathrm{HR}=1.65) .{ }^{21}$ Forman-Hoffman et al report a $50 \%$ higher risk of mortality in people with disabilities, in a representative study of the American population aged 18 or over. ${ }^{22}$ Wu et al report an adjusted HR of 2.23 in a follow-up study of a representative sample of American older people. ${ }^{23}$ Finally, Park et al found $57 \%$ higher adjusted mortality in the disabled group in a large all-age Korean population. ${ }^{24}$

The study of mortality associated with disability is complex due to the nature of the determinants of disability and its consequences. These determinants are both numerous and varied

Table 2 Mortality rates (per 1000 person-years), rate differences and rate ratios standardised to the baseline total population distribution of age, sex, living with a partner and education

\begin{tabular}{|c|c|c|c|c|}
\hline & SR disability & SR no disability & SRD & SRR \\
\hline Total & 20.03 (18.99-21.07) & $8.47(8.22-8.72)$ & $11.56(10.52-12.60)$ & $2.37(2.24-2.50)$ \\
\hline Women & $17.04(15.89-18.19)$ & $7.19(6.88-7.51)$ & $9.85(8.68-11.02)$ & $2.37(2.19-2.56)$ \\
\hline Men & $23.27(21.6-24.95)$ & $9.78(9.45-10.12)$ & $13.49(11.8-15.18)$ & $2.38(2.20-2.57)$ \\
\hline Age $18-39$ years & $3.00(1.91-4.09)$ & $0.45(0.38-0.51)$ & $2.55(1.46-3.65)$ & $6.72(4.55-9.93)$ \\
\hline Age $40-64$ years & $13.23(11.89-14.57)$ & $3.90(3.71-4.1)$ & 9.33 (7.97-10.68) & $3.39(3.02-3.80)$ \\
\hline Age $65-74$ years & $40.44(37.48-43.39)$ & 17.51 (16.67-18.36) & $22.92(19.85-25.99)$ & $2.31(2.12-2.52)$ \\
\hline Age $\geq 75$ years & $120.86(117.16-124.56)$ & $57.78(55.83-59.73)$ & $63.08(58.87-67.28)$ & $2.09(2.00-2.19)$ \\
\hline
\end{tabular}

SR, standardised rate; SRD, standardised rate difference; SRR, standardised rate ratio. 


\begin{tabular}{|c|c|c|c|}
\hline No of disabilities & $\mathrm{SR}^{*}$ & SRD & SRR \\
\hline 0 & $8.49(8.24-8.74)$ & 0 (ref.) & 1 (ref.) \\
\hline $1-3$ & $13.53(12.43-14.63)$ & $5.04(3.94-6.14)$ & $1.59(1.47-1.73)$ \\
\hline $4-9$ & $19.20(17.48-20.92)$ & $10.71(8.98-12.43)$ & $2.26(2.06-2.48)$ \\
\hline $10-42$ & $42.54(38.37-46.72)$ & $34.06(29.88-38.23)$ & $5.01(4.53-5.54)$ \\
\hline
\end{tabular}

*SR per 1000 person-years, with the baseline total population distribution of age, sex, living with a partner and education as standard.

SR, standardised rate; SRD, standardised rate difference; SRR, standardised rate ratio.

and the causal paths equally intricate. ${ }^{325}$ Some diseases lead to disability but are also associated with higher mortality through mechanisms that do not involve disability; they may behave as confounding factors. On the other hand, disability itself can increase the risk of certain conditions that could increase the risk of death, as mentioned in the introduction. Therefore, they could be considered mediators in the causal pathway from disability to mortality and should not be controlled for. We believe that greater part of the effect of disability health determinants on mortality is mediated by disability itself and a smaller part leads to death by paths that do not include disability.

The analysis appears to reveal some systematic patterns. With the SRR being relatively invariant across sexes and higher at ages $<65$ years, it would appear that disability-related causes of death in the adult population were different than the most notable causes of disability among older people, that is, dementia, stroke and depression, among others. The 10 -fold SRR increase we found for severity when the latter was measured with our ICF score might indicate a role for activity limitations as risk-of-death determinants; our ICF score was mainly based on ICF activities and did not include visual and auditory impairments. The interplay between activity limitations and medical care has yet to be mapped as a crucial part of coordinating health and social services, which is frequently

Table 5 Association of disability with mortality by group of causes

\begin{tabular}{|c|c|c|}
\hline Group of causes & SRD $(95 \% \mathrm{CI})^{*}$ & SRR $(95 \% \mathrm{Cl})$ \\
\hline Certain infectious and parasitic diseases & 0.28 (0.14 to 0.42$)$ & 3.38 (2.27 to 5.01$)$ \\
\hline Neoplasms & 2.13 (1.65 to 2.61$)$ & 1.74 (1.57 to 1.92$)$ \\
\hline $\begin{array}{l}\text { Diseases of the blood and blood-forming } \\
\text { organs and certain disorders involving } \\
\text { the immune mechanism }\end{array}$ & $0.02(-0.00$ to 0.05$)$ & $1.75(0.94$ to 3.26$)$ \\
\hline $\begin{array}{l}\text { Endocrine, nutritional and metabolic } \\
\text { diseases }\end{array}$ & 0.45 (0.33 to 0.57$)$ & $3.08(2.43$ to 3.90$)$ \\
\hline Mental and behavioural disorders & $0.40(0.28$ to 0.53$)$ & $2.43(1.91$ to 3.07$)$ \\
\hline Diseases of the nervous system & 1.46 (1.13 to 1.79$)$ & 4.86 (3.93 to 6.01$)$ \\
\hline Diseases of the circulatory system & $3.24(2.78$ to 3.71$)$ & 2.32 (2.12 to 2.55$)$ \\
\hline Diseases of the respiratory system & 1.42 (1.17 to 1.66$)$ & 2.69 (2.35 to 3.07$)$ \\
\hline Diseases of the digestive system & 0.56 (0.38 to 0.73$)$ & 2.25 (1.84 to 2.75$)$ \\
\hline $\begin{array}{l}\text { Diseases of the skin and subcutaneous } \\
\text { tissue }\end{array}$ & $0.03(0.00$ to 0.05$)$ & $2.38(1.22$ to 4.64$)$ \\
\hline $\begin{array}{l}\text { Diseases of the musculoskeletal system } \\
\text { and connective tissue }\end{array}$ & 0.20 (0.09 to 0.31$)$ & 3.45 (2.18 to 5.47$)$ \\
\hline Diseases of the genitourinary system & 0.51 (0.37 to 0.65$)$ & 3.10 (2.44 to 3.94$)$ \\
\hline $\begin{array}{l}\text { Congenital malformations, deformations } \\
\text { and chromosomal abnormalities }\end{array}$ & 0.05 (0.01 to 0.10$)$ & 28.23 (5.86 to 135.96$)$ \\
\hline $\begin{array}{l}\text { Symptoms, signs and abnormal clinical } \\
\text { and laboratory findings, not elsewhere } \\
\text { classified }\end{array}$ & 0.32 (0.19 to 0.46$)$ & 2.73 (2.01 to 3.71$)$ \\
\hline External causes & $0.47(0.26$ to 0.69$)$ & 2.68 (1.98 to 3.65$)$ \\
\hline
\end{tabular}

*SRD, per 1000 person-years, with the baseline total population distribution of age, sex, living with a partner and education as the standard.

SRD, standardised rate difference; SRR, standardised rate ratio. mentioned as a prominent but relatively little-known field of primary care. Understanding the relevance of specific activity limitations for determining risk of death when interacting with environmental (living alone, institutionalised, homebound, etc) or personal (literacy) factors may constitute grounds for increased surveillance of non-assisted disability persons, as has been proposed for primary care. ${ }^{26}$ In addition, large-scale epidemiological research could identify limitations in mobility, domestic activities or self-care associated with risk of death, as well as their potential underlying pathophysiological mechanisms.

This study has strengths that deserve to be mentioned. First, the very large sample size notably limits random errors. Second, interviewers specifically trained for the survey obtained disability assessments in the subjects' homes and we obtained mortality data from the INE. All of this greatly limits the possibility of bias. Finally, the representativeness of the sample improves the external validity of the study. Our study has several limitations. First, there was no information on mortality for $20 \%$ of the sample. However, we believe that the expected biasing impact on the estimates will be small, mainly because these missing data were due to problems in the identification of subjects, and thus we can reasonably assume that they are randomly distributed. Second, we were unable to make the adjustment more comprehensive, and our estimates may consequently suffer from residual confounding. However, we do not expect this problem to be quantitatively important, when considered in comparison with the estimates found in similar studies with adjustment for health variables. In addition, we found that the mortality rate increased in the disability group for almost every cause of death. Third, individuals' disability status was self-reported, and this can be a source of both over-reporting and under-reporting. However, it is expected that this potential misclassification would have diluted the strength of the estimations. Finally, we could not include the institutionalised population. Neglecting the institutionalised severely disabled, $1 / 5$ of the overall group ${ }^{26}$ may have led to an underestimation of SRD and the attributable fraction.

\section{CONCLUSION}

People with disability in this study clearly suffer from a higher risk of death than people without disability_some causes of death present an especially high risk for this population, such as neurological

\section{What is already known on this subject}

- There are many studies that present data on mortality associated with disability, but few have focused on measuring this association in large representative samples of populations. These few studies have found mortality rates between $50 \%$ and $100 \%$ higher in disability populations as compared with non-disability populations.

\section{What this study adds}

In a large, long-term follow-up study, we provide information on the risk of all-cause and cause-specific mortality associated with disability, including analyses of associations with disability severity. We report that clearly higher mortality was associated with disability, both in absolute and relative measures. Thus, preventive and health promotion measures are imperative to reduce the mortality in these populations. 
diseases and diabetes mellitus. In absolute terms, the number of deaths attributable to disability may also be considered very high. Thus, it would be advisable to implement adequate preventive measures and health promotion initiatives, to help both improve survival and offer better quality of life to people with disability.

Contributors JD and JA-I designed the study and directed its implementation, including quality assurance and control; JD and AP-M wrote the manuscript; JD and RP-B developed and wrote the methods; JdP-C and FJGL provided relevant ideas in the implementation of the article and collaborated in the development of the manuscript; JD is responsible for the overall content as the guarantor. All authors have given final approval to the manuscript.

Funding This work was supported by grant PI20CIII00045 from the Institute of Health "Carlos III"

Disclaimer This article presents independent research. The views expressed are those of the author(s) and not necessarily those of the Institute of Health Carlos III. The degree of accuracy or reliability of the quantitative information derived from this work is the sole responsibility of the authors and not of the institution that provides the data, the Spanish Statistical Office (Instituto Nacional de Estadística).

Competing interests None declared.

Patient consent for publication Not applicable.

Ethics approval The study was approved by the Institute of Health Carlos III Ethics Committee.

Provenance and peer review Not commissioned; externally peer reviewed.

Data availability statement No data are available due to legal restrictions.

Supplemental material This content has been supplied by the author(s). It has not been vetted by BMJ Publishing Group Limited (BMJ) and may not have been peer-reviewed. Any opinions or recommendations discussed are solely those of the author(s) and are not endorsed by BMJ. BMJ disclaims all liability and responsibility arising from any reliance placed on the content. Where the content includes any translated material, BMJ does not warrant the accuracy and reliability of the translations (including but not limited to local regulations, clinical guidelines, terminology, drug names and drug dosages), and is not responsible for any error and/or omissions arising from translation and adaptation or otherwise.

Open access This is an open access article distributed in accordance with the Creative Commons Attribution Non Commercial (CC BY-NC 4.0) license, which permits others to distribute, remix, adapt, build upon this work non-commercially, and license their derivative works on different terms, provided the original work is properly cited, appropriate credit is given, any changes made indicated, and the use is non-commercial. See: http://creativecommons.org/licenses/by-nc/4.0/.

\section{ORCID iDs}

Javier Damián http://orcid.org/0000-0002-6258-8220

Alicia Padron-Monedero http://orcid.org/0000-0002-0709-5757

\section{REFERENCES}

1 World Health Organization. Disability and health, 2018. Available: https://www.who. int/news-room/fact-sheets/detail/disability-and-health [Accessed 1 May 2021].

2 Centers for Disease Control and Prevention. Disability and health, 2020. Available: https://www.cdc.gov/ncbddd/disabilityandhealth/disability.html [Accessed 1 May 2021].

3 World Health Organization/World Bank. World report on disability 2011, 2011. Available: https://www.who.int/disabilities/world_report/2011/report/en/ [Accessed 1 May 2021].
4 Kinne S, Patrick DL, Doyle DL. Prevalence of secondary conditions among people with disabilities. Am J Public Health 2004;94:443-5.

5 US Department of Health and Human Services. The surgeon general's call to action to improve the health and wellness of persons with disabilities. US department of health and human services, office of the surgeon general. Office of the Surgeon General 2005 https://www.ncbi.nlm.nih.gov/books/NBK44667/

6 Rimmer JH, Braddock D, Fujiura G. Prevalence of obesity in adults with mental retardation: implications for health promotion and disease prevention. Ment Retard 1993:31:105-10

7 Nosek MA. The John Stanley Coulter lecture. Overcoming the odds: the health of women with physical disabilities in the United States. Arch Phys Med Rehabil 2000:81:135-8.

8 Beller J, Epping J. Disability trends in Europe by age-period-cohort analysis: increasing disability in younger cohorts. Disabil Health J 2021:14:100948.

9 Instituto Nacional de Estadística. Survey on Disability, Personal Autonomy and Dependency Situations 2008, 2010. Available: https://www.ine.es/dyngs/INEbase/ en/operacion.htm?c=Estadistica_C\&cid=1254736176782\&idp=1254735573175\& menu=metodologia\# [Accessed 1 May 2021].

10 World Health Organization. World Health Organization: ICF Checklist Version2.1A., 2009. Available: http://www.who.int/classifications/icf/training/icfchecklist.pdf [Accessed 1 May 2021].

11 Maierhofer S, Almazán-Isla J, Alcalde-Cabero E, et al. Prevalence and features of ICF-disability in Spain as captured by the 2008 national disability survey. BMC Public Health 2011;11:897.

12 World Health Organization. The Startup mortality list (ICD-10-SMoL), 2018. Available: https://www.who.int/healthinfo/civil_registration/smol/en/[Accessed 1 May 2021].

13 Instituto Nacional de Estadística. Lista reducida de causas de muerte CIE-10 Y SU correspondencia Con La CIE-9, 2020. Available: https://www.ine.es/daco/daco42/ sanitarias/lista_reducida_CIE10.pdf [Accessed 1 May 2021].

14 Robins JM, Hernán MA, Brumback B. Marginal structural models and causal inference in epidemiology. Epidemiology 2000;11:550-60.

15 Hernán MA, Robins JM. Estimating causal effects from epidemiological data. J Epidemiol Community Health 2006;60:578-86.

16 Miettinen OS. Proportion of disease caused or prevented by a given exposure, trait or intervention. Am J Epidemiol 1974;99:325-32.

17 Sato T, Matsuyama Y. Marginal structural models as a tool for standardization. Epidemiology 2003;14:680-6.

18 Greenland S. Re: "Confidence limits made easy: interval estimation using a substitution method". Am J Epidemiol 1999:149:884.

19 StataCorp. Stata statistical software: release 15. Coll Stn TX Stata Corp LCC, 2017.

20 Instituto Nacional de Estadística. Population figures, 2020. Available: https://www.ine es/dyngs/INEbase/en/operacion.htm?c=Estadistica_C\&cid=1254736176951\&menu= ultiDatos\&idp=1254735572981 [Accessed 1 May 2021].

21 Majer IM, Nusselder WJ, Mackenbach JP, et al. Mortality risk associated with disability: a population-based record linkage study. Am J Public Health 2011;101:e9-15

22 Forman-Hoffman VL, Ault KL, Anderson WL, et al. Disability status, mortality, and leading causes of death in the United States community population. Med Care 2015:53:346-54

23 Wu L-W, Chen W-L, Peng T-C, et al. All-cause mortality risk in elderly individuals with disabilities: a retrospective observational study. BMJ Open 2016;6:e011164.

24 Park JM, Oh U, Roh B-R, et al. Disparities in mortality by disability: an 11-year followup study of 1 million individuals. Int J Public Health 2017;62:989-96.

25 McDermott S, Turk MA. The myth and reality of disability prevalence: measuring disability for research and service. Disabil Health J 2011;4:1-5.

26 Almazán-Isla J, Comín-Comín M, Alcalde-Cabero E, et al. Disability, support and long-term social care of an elderly Spanish population, 2008-2009: an epidemiologic analysis. Int J Equity Health 2017;16:4. 